\title{
Placental polyp: a diagnostic dilemma
}

\section{Sravani Chithra. Ch*, Rahul Manchanda, Anshika Lekhi, Nidhi Jain}

Department of Gynaecology Endoscopy Unit, Manchanda's Endoscopic Centre, PSRI Hospital, Delhi, India

Received: 26 April 2016

Revised: 15 June 2016

Accepted: 18 June 2016

\section{*Correspondence:}

Dr. Sravani Chithra. Ch,

E-mail: drsravanichithra@yahoo.com

Copyright: (C) the author(s), publisher and licensee Medip Academy. This is an open-access article distributed under the terms of the Creative Commons Attribution Non-Commercial License, which permits unrestricted non-commercial use, distribution, and reproduction in any medium, provided the original work is properly cited.

\begin{abstract}
Placental polyp is the retained fragment of placental tissue after parturition or abortion for indefinite period which forms a polypoidal mass in the uterus. It has an incidence of less than $0.25 \%$ of all pregnancies. It is predominantly composed of necrotic and hyalinized chorionic villi. These pedunculated masses present within days to weeks following an abortion or delivery of a term placenta. The patient presents with abnormal uterine bleeding and slightly elevated detectable titers of serum $\beta$-human chorionic gonadotropin $(\beta \mathrm{HCG})$. Here we have reviewed the literature of placental polyp regarding its pathogenesis, diagnosis and management. The authors would like to stress the importance of hysteroscopy in diagnosis and management of placental polyp that can be missed on ultrasound and blind procedure like curettage and histopathology that gives a confirmatory diagnosis.
\end{abstract}

Keywords: Curettage, Placental polyp, Histopathology, Hysteroscopy, Ultrasound

\section{INTRODUCTION}

Placental polyp is the retained fragment of placental tissue after parturition or abortion for an indefinite period resulting in the formation of a polypoidal mass in the uterus. It is predominantly composed of necrotic and hyalinized chorionic villi.

It is a rare entity and its estimated incidence is around 1 in 40,000-60,000 deliveries.

It presents as a polypoidal or pedunculated mass within the uterus and is attached to the uterine cavity on a broad base or by a thin pedicle.

Most commonly, placental polyps occur after therapeutic abortion and spontaneous delivery. It is extremely rare after spontaneous abortion. ${ }^{2}$

Patients usually present with symptoms like heavy bleeding or dirty discharge per vaginum dating back to time of childbirth or miscarriage.
Diagnosis is usually made by colour doppler ultrasound. ${ }^{3}$

The best method to make the diagnosis and manage a placental polyp conservatively would be to do a diagnostic hysteroscopy and resect the polyp under vision and then confirm the diagnosis by histopathology.

\section{Review of literature}

In everyday clinical practice, it is not uncommon for patients to suffer from major vaginal bleeding, abdominal pain, or fever a few days after vaginal delivery, caesarean section, or curettage following an abortion.

Placental polyp is a rare pathology encountered in day to day practice with an incidence of less than $0.25 \%$ of all pregnancies. ${ }^{4}$ Hence is not thought of as the first possible diagnosis when a patient presents with bleeding per vaginum. 
In 1884 Baer reported a case of placental polyp that occurred 12 years after the pregnancy and this entity has been recognized since then. ${ }^{5}$

Placental polyps are of two types. Acute type which occurs in the first four weeks after parturition and the one which occurs months or years later is termed as chronic type. Acute type of placental polyps are more common. ${ }^{6,7}$

\section{Pathogenesis}

A placental polyp is an intrauterine polypoid mass occurring due to organization of the residual placental fragments following surgical abortion, caesarean section, or vaginal delivery. ${ }^{8}$

It slows down postnatal involution of uterus and contributes to development of endometritis and metrorrhagia. It enlarges in size due to accumulation of blood clots and fibrin products over several weeks to several months after delivery.

Pathogenesis of the placental polyps has been explained by two major theories.

According to the first theory, by Ranney, he attributed to the thickness and tone of myometrium in different areas and that the myometrium beneath the placental site was thinner than that of opposing wall. The fundal and utero tubal areas have reduced muscle mass and are relatively atonic after second stage of labor which explains the phenomenon of retained placenta.

Ranney believed that significant numbers of retained placentas were implanted high in cornual areas. Of 1500 deliveries, he reported 62 cases of retained placenta of which $45(72.6 \%)$ were implanted in corneal region. ${ }^{9}$

According to the second theory by Eastman and Hellman, the placenta is sometimes attached to the cornual or fundal myometrium and is easily retained as the myometrium in this region is thin and atonic and the chorionic villi attach themselves directly to the underlying myometrium as a result of defective decidua. $^{10}$

Hence the cornua or fundus becomes the most common sites for the placental polyps.

Two pathogenic mechanisms of uterine haemorrhage have been established by Milovanov et al. ${ }^{5}$

First one is that, the preservation of brush border of the synctiotrophoblasts with the presence of placental phosphatase maintains the anti-coagulative property of villi. This appears in cases of post-abortion haemorrhage and preserved cotyledons.

Second mechanism is that the thromboplastic properties of the retained villi play a leading role in the pathogenesis of uterine haemorrhage in the scrapes wherein the necrotic villi with epithelial remains are prevalent, similar to the hypocoagulative phase of isolated chronic disseminated intravascular coagulation.

\section{Pathology}

Remnants of placenta or membrane attached to the uterine wall and fibrin deposition around the remnants are usually considered pathognomonic of the formation of placental polyps. $^{11}$

Placental polyp has the trend for neovascularization and increase in vascularity. The sudden occurrence of uterine bleeding is thought to be a result of the rupture of abnormal blood vessels formed as a result of neovascularisation. Thus uterine bleeding occurs as the main symptom with this disease.

Histologically, the placental polyp contains predominantly the ghost villi which are hyalinized and necrotic, and without lining trophoblasts. Some of the chorionic villi may show a rim of synctiotrophoblasts that are viable. The base of the placental polyp contains abundant decasualized stromal with dilated and congested blood vessels (Figure 1).

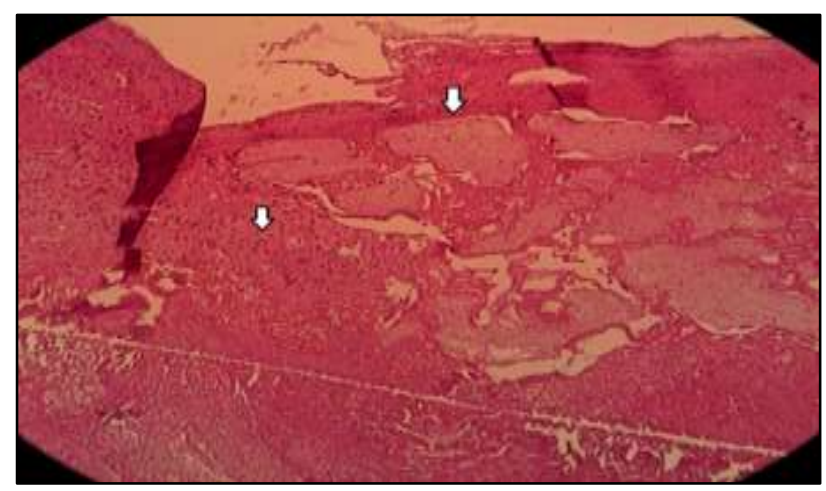

Figure 1: Histopathology of decidua and necrotic villi.

Diagnosis is made pre operatively from a typical history, serum $\beta \mathrm{HCG}$ and imaging.

Patients usually give a typical history of miscarriage with history of curettage or recent history of delivery, followed by heavy bleeding per vaginum.

The factors responsible for the survival of these villi are still not clear however these surviving villi are responsible for the production of the human chorionic gonadotropin (HCG). BHCG was elevated in the case reports discussed by Swan RW et al and Shanthi V et al. $^{12,13}$

The diagnosis is made using various imaging modalities like USG with colour doppler signal, magnetic resonance imaging (MRI) and computed tomographic angiography. 
USG imaging with colour doppler of the placental polyp shows a heterogeneous polypoid mass with prominent vascular flow (Figure 2).

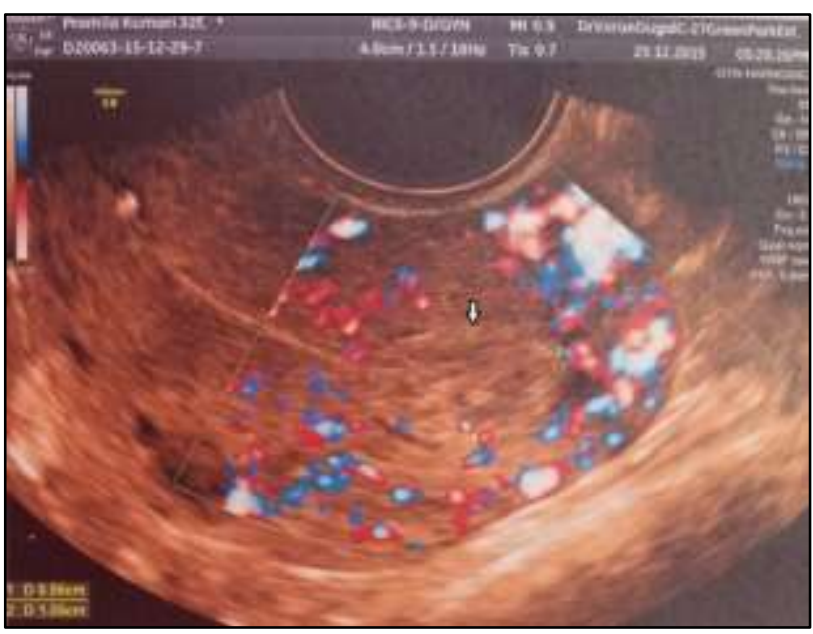

Figure 2: Ultrasonography of polyp with vascular pedicle.

Van den Bosch $\mathrm{T}$ et al did a prospective study to evaluate the occurrence of residual trophoblastic tissue after miscarriage or delivery, to assess the diagnostic value of sonography with colour doppler examination in the detection of retained tissue, and to define in what cases expectant management may be an option. ${ }^{14}$

In total, 1070 patients were assessed. In 67 patients (6.3\%), sonographic and colour doppler examination showed retained tissue as areas of enhanced myometrial vascularity. In all but 1 case, retained tissue was confirmed on histologic examination. Thus they concluded that sonography with colour doppler examination is clinically useful to confirm or exclude residual trophoblastic tissue.

Hiraki K et al also concluded that use of colour doppler ultrasound may be useful in diagnosing placental polyp. ${ }^{15}$

MRI can more accurately detect the abundant blood supply follow-up of placental polyps. ${ }^{16}$

Computed tomographic angiography is also useful in diagnosis and management of placental polyp with neovascularization.

Takeda A et al showed that Evaluation of neovascularization by multimodal imaging is potentially useful in management of placental polyp in a woman who wishes to preserve fertility. ${ }^{17}$

Takeda A et al in another study included seventeen women with suspected placental polyp in this retrospective study. Neovascularization in placental polyp tissue was assessed by computed tomographic angiography. Of 17 patients with suspected placental polyp after abortion or parturition, nine patients were diagnosed to have placental polyp with prominent neovascularization by computed tomographic angiography, and were treated by uterine artery embolization followed by hysteroscopic resection. Two patients subsequently conceived after conservative management. After precise evaluation of neovascularization by computed tomographic angiography, hysteroscopic resection with preoperative uterine artery embolization is an effective minimally invasive procedure to conservatively treat placental polyp with prominent neovascularization. ${ }^{18}$

Recently, there are some reports indicating that 3-D computed tomography angiography can be useful in diagnosing placental polyps and in determining a treatment plan. ${ }^{19}$

Umezu $\mathrm{T}$ et al showed that 3D-CT angiography clearly demonstrated the 3-D features of the feeding artery, the draining vein, and the surrounding normal structures. The diagnosis in patient 1 was a uterine arteriovenous malformation, in patient 2 was a placental polyp mimicking a uterine arteriovenous malformation, and in patient 3 was a placental polyp. Patients were all successfully treated with trans-cervical resection of the placental polyp. They concluded that 3D-CT angiography is useful for making a differential diagnosis and for preoperative planning in patients with post-abortion uterine hemorrhage. ${ }^{19}$

American society for reproductive medicine concluded that 'evaluation of neovascularization by multimodal imaging is potentially useful in the management of placental polyp in a woman who wishes to preserve fertility'.

Though there is availability of serum marker and imaging modalities, the preoperative diagnosis of placental polyp is rarely made.

\section{Management}

This clinical event could be life-threatening for the patient and sometimes may require an emergency hysterectomy.

Profuse haemorrhage and hypovolemic shock are the most feared complications. Prompt resuscitation, control of bleeding, and complete removal are paramount must be done in this situation.

In such cases, selection of a proper treatment method seems to be difficult. Most patients would prefer uterus preserving surgery and hysterectomy has almost become obsolete.

Management has traditionally been dilatation and curettage, often guided by sonography. However, in these patients, tissue is usually attached to a small area of the 
endometrium and tissue evacuation is incomplete, thus bleeding or symptoms may persist.

Using hysteroscopy, this area can be selectively targeted and removed, without damaging the intact endometrium.

Hence hysteroscopic removals of placental polyp, uterine artery embolization and in some cases, a combination of these procedures have been proposed as surgical methods with the intention to preserve the uterus. ${ }^{20,21}$

Dyer I et al in their retrospective study concluded that after precise evaluation of neovascularization by computed tomographic angiography, hysteroscopic resection with preoperative uterine artery embolization is an effective minimally invasive procedure to conservatively treat placental polyp with prominent neovascularization. ${ }^{22}$

Jimenez JS et al in their study concluded that diagnosticoperative ambulatory hysteroscopy is a suitable alternative to blind curettage in the management of retained trophoblastic tissue. This technique can be performed in the office without anaesthesia and with a low rate of complications. ${ }^{23}$

Takeda A et al concluded that after precise evaluation of neovascularization by computed tomographic angiography, hysteroscopic resection with preoperative uterine artery embolization is an effective minimally invasive procedure to conservatively treat placental polyp with prominent neovascularization. Two patients subsequently conceived after conservative management. ${ }^{18}$

With appropriate treatment, the prognosis of Placental Polyp is excellent.

\section{CONCLUSION}

Placental polyp should be considered in any case of parous woman with unexplained abnormal uterine bleeding and slightly elevated serum hCG level. The history of the last pregnancy is sometimes very remote. This however does not exclude the possibility of the presence of a placental polyp as the source of abnormal bleeding.

Ultrasonography with colour doppler examination can be used to confirm or exclude residual trophoblastic tissue. Although sonography shows a polyp, it is not helpful in differentiating the polyps from other masses in the uterus such as hydatidiform moles or degenerated sub-mucosal uterine leiomyoma's.

To preserve fertility and lessen morbidity in the cases of placental polyp, an optimal investigation and management with efficient planning is required.
An optimal investigation to confirm the diagnosis preoperatively is not available but multimodal method can help come to a provisional diagnosis.

Per-operatively hysteroscopy helps us to view the placental polyp as an aggregated mass of retained products. Hysteroscopic resection of placental polyp is an effective minimally invasive procedure to conservatively treat the pathology with minimal complications.

Histopathological examination of tissue is required to ascertain and confirm the diagnosis.

Funding: No funding sources

Conflict of interest: None declared

Ethical approval: Not required

\section{REFERENCES}

1. Watcharotone W, Leelaphatanadit C. Placental polyp: a case report. Siriraj Med J. 2005;57:391-2.

2. Kaneko M, Harima H, Okagaki R, Hosoya I, Shigemitsu S, Kasahara K, et al. A case of placental polyp developed immediately after spontaneous abortion. Nippon Sanka Fujinka Gakkai Zasshi. 1992;44:255-7.

3. Palat P, Suma S, Kantarcy M, Alper F, Levent A. Colour doppler US in the evaluation of uterine vascular abnormalities. Radio Graphics. 2002;22:4753.

4. Milovanov AP, Kirsanov IN. The pathogenesis of uterine hemorrhages in the so-called placental polyps. Arkh Patol. 2008;70:34-7.

5. Baer BF. Placental polypus which simulated malignant disease of the uterus. Philadelphia Med Times. 1884;15:175.

6. Dorsey CW. Placental polyp with severe late puerperal hemorrhage. Am J Obst and Gynec. 1942;44:591.

7. Hagstorm HT. late puerperal hemorrhage due to placental polyp. Am J Obst and Gynec. 1940;39:879.

8. Hoberman LK, Hawkinson JA, Beecham CT. Placental polyp: report of 3 cases. Obstet Gynecol. 1963;22:25-9.

9. Ranney B. Relative atony of myometrium underlying the placental site secondary to high corneal implantation, a major cause of retained placentas. Amer J Obstet Gynec. 1956;71:1049.

10. Eastman N, Hellman LM. Williams obstetrics. Appleton New York; 1966.

11. Yi JG, Choi SE, Shin YK, Lee JH. Placental polyp: Sonographic findings. Am J Radiol. 1993;161:345-6.

12. Swan RW, Woodruff JD. Retained products of conception. Histologic viability of placental polyps. Obstet Gynecol. 1969;34:506-14.

13. Shanthi V, Rao NM, Lavanya G, Krishna BR, Mohan KM. Placental polyp-a rare case report. Turk Patoloji Derg. 2015;31:77-9.

14. Van den Bosch T, Daemen A, Van Schoubroeck D, Pochet N, De Moor B, Timmerman D. Occurrence 
and outcome of residual trophoblastic tissue: a prospective study. J Ultrasound Med. 2008;27(3):357-61.

15. Hiraki K, Khan KN, Kitajima M, Fujishita A, Masuzaki H. Uterine preservation surgery for placental polyp. J Obstet Gynaecol Res. 2014;40(1): 89-95.

16. Kurachi H, Maeda T, Murakami T, Tsuda K, Sakata M, Nakamura H, et al. MRI of placental polyps. J Comput Assist Tomogr. 1995;19:444-8.

17. Takeda A, Koyama K, Imoto S, Mori M, Sakai K, Nakamura H. Placental polyp with prominent neovascularization. Fertil Steril. 2010;93:1324-6.

18. Takeda A, Koyama K, Imoto S, Mori M, Sakai K, Nakamura H. Computed tomographic angiography in diagnosis and management of placental polyp with neovascularization. Arch Gynecol Obstet. 2010;281:823-8.

19. Umezu T, Iwase A, Ota T, Suzuki K, Nakagawa A, Nakahara $T$, et al. Three dimensional CT angiography is useful for diagnosis of postabortion uterine hemorrhage: 3 case reports and review of the literature. J Minim Invasive Gynecol. 2010;17:24651.

20. Takeuchi K, Ichimura H, Masuda Y, Yamada T, Nakago S, Maruo T. Selective trans-arterial embolization and hysteroscopic removal of a placental polyp with preservation of reproductive capacity. J Reprod Med. 2002;47:608-10.

21. Takeuchi K, Sugimoto M, Kitao K, Yoshida S, Maruo T. Pregnancy outcome of uterine arterial embolization followed by selective hysteroscopic removal of a placental polyp. Acta Obstet Gynecol Scand. 2007;86:22-5.

22. Dyer I, Bradburn DM. An inquiry into the etiology of placental polyps. Am J Obstet Gynecol. 1971;109:858-67.

23. Jimenez JS, Gonzalez C, Alvarez C, Munoz L, Perez $\mathrm{C}$, Munoz JL. Conservative management of retained trophoblastic tissue and placental polyp with diagnostic ambulatory hysteroscopy. Eur J Obstet Gtnecol Reprod Biol. 2009;145:89-92.

Cite this article as: Chithra. SCh, Manchanda $\mathrm{R}$, Lekhi A, Jain N. Placental polyp: a diagnostic dilemma. Int J Reprod Contracept Obstet Gynecol 2016;5:2069-73. 